\title{
PRIVATIZAÇÃO DA E NA EDUCAÇÃO INFANTIL: PERSPECTIVAS EM DIÁLOGO
}

\author{
PRIVATIZATION OF AND IN CHILDHOOD EDUCATION: PERSPECTIVES IN DIALOGUE
}

\author{
PRIVATIZACIÓN DE LA E EN LA EDUCACIÓN INFANTIL: PERSPECTIVAS EN EL DIÁLOGO
}

\author{
Cassia Domiciano ${ }^{1}$ \\ ORCID: https://orcid.org/0000-0003-3030-2416 \\ Theresa Adrião ${ }^{2}$ \\ ORCID: https://orcid.org/0000-0003-1181-5873
}

A defesa pela efetivação do direito à educação é pauta histórica das educadoras e educadores, pesquisadoras e pesquisadores, movimentos sociais e entidades coletivas brasileiras. Em um avanço inédito, mesmo quando comparado a países desenvolvidos, a Constituição Federal de 1988 garantiu a creche e a pré-escola como direito da criança e dever do Estado, sendo inegáveis os avanços decorrentes dessa declaração constitucional nos últimos trinta anos, como por exemplo, expansão do acesso, garantia de financiamento público e reconhecimento da criança como sujeito de direitos, condições estas reafirmadas pelo Estatuto da Criança e do Adolescente (ECA - Lei 8.069/1990), pela Lei de Diretrizes e Bases da Educação Nacional (LDBN) 9.394/1996 e pela inscrição da educação infantil na política de financiamento da educação a partir do Fundo de Manutenção e Desenvolvimento da Educação Básica e de Valorização dos Profissionais da Educação (FUNDEB), em dezembro de 2006.

A materialização dessas conquistas em normas e políticas pouco tinha prosperado quando o Estado brasileiro anunciava novo ciclo de reformas. Inspiradas nas perspectivas da Nova Gestão Pública (JUNQUILHO, 2002; 2004; GARCIA; ADRIÃO; BORGHI, 2009; OLIVEIRA, 2015), as propostas reformadoras inscritas no Plano Diretor de Reforma do Aparelho de Estado (PDRAE), apresentado no primeiro mandato do presidente Fernando Henrique Cardoso (1995-1998), formalizaram-se através de um conjunto de leis e decretos que permitiram a ampliação do protagonismo e a ação do setor privado para garantia dos direitos sociais (PERONI; ADRIÃO, 2005; PERONI; OLIVEIRA; FERNANDES, 2009). Na área da Educação, dentre outras ações, testemunhamos a transferência da responsabilidade pela oferta educacional para as municipalidades, processo conhecido por municipalização da educação OLIVEIRA, 1999) - entes federados com menor capacidade fiscal -; a expansão da presença do setor privado de base empresarial na definição das políticas (FREITAS, 2014); e a ampliação da transferência de fundos públicos para instituições privadas, lucrativas ou não, tendo em vista a transferência da oferta educativa, da gestão educacional e da elaboração e implementação de currículos (ADRIÃO, 2018).

Especificamente na Educação Infantil, tema deste dossiê, as reformas fomentaram a transferência da oferta educativa para organizações privadas, generalizando-se como estratégia governamental durante a vigência do FUNDEF (PINTO, 2007; ARELARO, 2008) - instituído pela Emenda Constitucional 14 de 1996 - que, dentre outras coisas, focalizou o financiamento educacional no ensino fundamental (PINTO, 2007; CORREA, 2011). Essa transferência da oferta educativa foi aprofundada com a EC 19 de 1998, que normalizou e induziu o financiamento público para oferta privada de serviços públicos por meio da celebração de contratos e convênios e da parceria público-

\footnotetext{
${ }^{1}$ Universidade Federal do Paraná. Curitiba, PR, Brasil. <cassia.domiciano@ufpr.br>
}

${ }^{2}$ Universidade Estadual de Campinas. Campinas, SP, Brasil. <theadriao@gmail.com.> 
privada, exigindo novo marco regulatório para adequar a gestão pública às orientações de cunho gerencial (ADRIÃO; BEZERRA, 2013; PIRES, 2015); a EC foi agravada posteriormente à Lei de Responsabilidade Fiscal - Lei Complementar 101/2000 - que, ao fixar um teto de gastos com despesa de pessoal, induziu a desresponsabilização do setor público para com a oferta direta da educação (DOMICIANO-PELLISSON, 2016; ADRIÃO, 2017; ADRIÃO; DOMICIANO, 2018). A esse cenário agregam-se as contradições introduzidas pelo FUNDEB - decorrente da EC 53 de 2006 -, que, ao mesmo tempo que inclui toda a educação infantil na dinâmica de financiamento do fundo, permitiu o repasses desses recursos ao setor privado não lucrativo (PINTO, 2007; ADRIÃO; BORGHI, 2008; DOMICIANO, 2009; BASSI, 2011; DOMICIANO, 2011; OLIVEIRA; BORGHI, 2013).

Às tendências de privatização, facilitadas pelo arcabouço legal, soma-se a fragilidade financeira da maior parte dos municípios brasileiros em virtude do modelo de arrecadação e repartição de impostos no Brasil, seja, conforme Rezende (2010), em decorrência da concentração espacial das bases tributárias modernas, seja pelas exigências de eficiência da tributação. Para o autor, "a ausência de um sistema de transferências orientado para a correção desses desequilíbrios agrava, ao invés de corrigir as disparidades decorrentes da concentração da atividade econômica." (REZENDE, 2010, p. 72). Desse modo, os entes federados mais pobres da esfera administrativa optam pela forma mais 'econômica' de garantir a expansão do atendimento das crianças pequenas, o qual, tradicionalmente, na creche, se assenta pela via do conveniamento (CAMPOS, 1989; CAMPOS; ROSEMBERG; FERREIRA, 2006).

Com demanda crescente, atendimento historicamente deficitário e sob a responsabilidade prioritária do ente federado financeira e tecnicamente mais frágil no Brasil, ampliam-se as formas de privatização na e da Educação Infantil. Por privatização da educação, entendemos com Hill (2003) as estratégias de reprodução do capital. Este, além de atuar no corte ou diminuição dos gastos públicos com saúde, educação, previdência, assistência social e outros da esfera social, procura também se ampliar e se reproduzir por meio da busca de novos mercados. Para o autor, há três estratégias ou Planos para ampliação do capital, dentre eles, "um Plano de Negócios na Educação: este se concentra em liberar as empresas para lucrar com a educação.” Neste caso, a educação pública é transformada em campo para realização de negócios.

No Brasil, estudos identificam variadas formas de privatização e, consequentemente, da lógica de mercado impregnada na expansão do atendimento, seja na oferta da educação básica financiada com recursos públicos por meio de parceria público-privada, tendo como exemplo a cidade de Belo Horizonte (ADRIÃO; BEZERRA, 2013) -, seja ainda nos processos de conveniamento da educação infantil e gestão privada de unidades públicas com subsídio governamental (SUSIN, 2006; BORGHI, 2012; DOMICIANO, 2012; DOMICIANO-PELLISSON, 2016; FRANCO; DOMICIANO; ADRIÃO, 2019), ou a venda de insumos curriculares por corporações e por segmentos a estes associados (ADRIÃO; DAMASO; GALZERANO, 2013; ADRIÃO, 2017).

Desse modo, intencionando explicitar as formas de privatização e os riscos advindos desses processos para o direito fundamental das crianças pequenas, reunimos neste dossiê, um conjunto de seis pesquisas, desenvolvidas por investigadores de diferentes lugares e contextos, oriundos de universidades brasileiras, de Portugal e Buenos Aires. Esperamos contribuir para o avanço do conhecimento na área e pautar a defesa de nossos pequenos no caminho até as unidades educacionais públicas e de qualidade.

Com uma síntese de dados de pesquisa concluída em 2018 em dez países da América Latina e Caribe - Argentina, Bolívia, Brasil, Colômbia, Costa Rica, Cuba, El Salvador, Honduras, México e República Dominicana -, o artigo El derecho a la educación y al cuidado em la primera infância: perspectivas desde America Latina y el Caribe, de Mercedes Mayol Lassale, Camila Croso e Giovanna Modé Magalhães, abre o dossiê trazendo ao público leitor um panorama das respostas dos países investigados aos princípios e propósitos inscritos na Convenção sobre os Direitos da Criança (CDC), que inaugura uma nova etapa sobre a concepção de infância e eleva as crianças e adolescentes como sujeitos de direitos. A materialidade das ações nesses países é apresentada e discutida pelas autoras a partir do levantamento das leis nacionais, das políticas de atendimento à primeira infância $(0-8$ anos) e do investimento despendido à faixa etária correspondente. Ressaltam as autoras que, apesar dos avanços, as políticas expressam grande heterogeneidade e fragmentação, colocando em risco a garantia do direito humano à Educação Infantil, principalmente quando se observam tendências privatizantes nos países investigados. 
Da América Latina e Caribe, passamos para Portugal com o artigo Articulações entre o público e o privado na Educação de Infância em Portugal, de Emília Vilarinho, no qual a autora analisa o papel do Estado português na promoção de políticas educativas para crianças de 3 a 6 anos e a sua relação com a promoção da igualdade em educação e com os direitos da criança. Dados de investigação anterior são atualizados, trazendo para o leitor as principais medidas de intervenção do Estado, a redefinição do seu papel no pós-Estado providência e como foi feita a construção da agenda para a Educação de Primeira Infância no país. A partir de dados de Lisboa e do Porto, Vilarinho evidencia que a educação para as crianças de 0-3 anos é majoritariamente privada, ainda vinculada ao Ministério do Trabalho e Segurança Social. No Jardim de Infância, a taxa de cobertura pelo Estado é maior, mas isso não significa atendimento público e gratuito, na medida em que Portugal avança na permissão de subvenção à esfera privada lucrativa e não lucrativa, mantendo e aprofundando modalidades, processos e "arranjos institucionais" que caracterizam a privatização da e na educação de infância.

$\mathrm{O}$ artigo Atuação dos governos dos estados de Alagoas e Maranbão no financiamento da educação infantil, de Nicanor Lopes, Theresa Adrião e Gabriela Cristina Ramos, chama a atenção para a fragilidade do regime de colaboração por parte dos estados e correlaciona esta ausência colaborativa à privatização e às desigualdades das condições de oferta nesta etapa da educação básica. Os autores apresentam inicialmente um panorama da oferta da Educação Infantil no período de 2005 a 2015 nos estados selecionados, explicitando a atuação das diferentes esferas administrativas. Posteriormente, a partir de um conjunto de insumos e infraestrutura selecionados com base no Custo Aluno Qualidade Inicial (CAQi) e no Índice de Condições de Oferta (ICOE), mostram a situação crítica da rede educacional maranhense e alagoana, principalmente no que concerne à creche. Complementando os dados e as análises, os autores discutem os gastos desses governos na subfunção educação infantil, destacando os empreendidos com o setor privado, explicitando o volume de recursos públicos drenados para aquele setor e a completa ausência de cooperação entre estados e municípios na promoção da Educação Infantil.

A oferta, a gestão e o financiamento educacional também são parte da análise do artigo Nova Gestão Pública e Programa Nave-mãe': caminhos comuns à privatização, de autoria de Cassia Domiciano. Por meio de pesquisa realizada no município de Campinas-SP, a autora mostra os efeitos da privatização da gestão de unidades públicas de Educação Infantil após a implantação do Programa de Atendimento Especial à Educação Infantil (PAEEI), comprovando a ascensão desse setor na definição das políticas locais, o direcionamento crescente de recursos públicos a esse segmento e a disputa entre as entidades privadas para gerir os equipamentos a fim de angariar volume maior de financiamento público. Avalia a autora que o PAEEI se assenta sob as perspectivas da Nova Gestão Pública, colocando em xeque o direito humano à educação.

Complementando a investigação sobre Campinas-SP, o artigo As instituições sem fins lucrativos na privatizaçãa da Educação Infantil, escrito por Maria Lúcia Lemos Ceccon e Nádia Pedrotti Drabach, focaliza a análise na natureza das instituições privadas que se tornaram atores de destaque na oferta da Educação Infantil e na gestão dos equipamentos públicos, principalmente depois de 2007, quando o município passou a priorizar o atendimento com gestão privada. Mostram as autoras que, ao longo do tempo, houve transformações político-normativas no que chamam de (re)constituição das instituições sem fins lucrativos, com vistas a ampliar o atendimento às demandas de Educação Infantil do município.

Destacando um "novo" nicho de mercado, o artigo A Educação Infantil sob a lógica do empreendedorismo e dos "Negócios de impacto Social", escrito por Bianca Correa, que fecha este dossiê, discute o material intitulado Empreendedorismo e negócios de impacto social para a Primeira Infância, publicado e organizado pela Fundação Maria Cecilia Souto Vidigal, cujo objetivo explícito é "apoiar empreendedores interessados em desenvolver negócios de impacto para a Primeira Infância”. Como destinatário de seus produtos de impacto social, está a população infantil em situação de vulnerabilidade, com destaque para as "creches e pré-escolas de baixo custo". De forma crítica, ao analisar o material, a autora destaca os novos desafios impostos à defesa de todas as crianças como sujeitos de direitos e ao enfretamento de sua subordinação a interesses contrários, na avaliação de Correa, expressos na sua transformação em "meras mercadorias, ou, exagerando numa analogia, commodities."

Nesta conjuntura, na qual o Congresso debate o NOVO-Fundeb - e, novamente, somos convocados a refletir e incidir na defesa da educação infantil como direito dos pequenos/as e adequado a seus interesses e necessidades -, a Educação em Revista publica este dossiê, cujo conteúdo, 
acreditamos, contribui para o avanço das pesquisas sobre políticas públicas para a primeira infância, para o diálogo informado entre pesquisadoras e pesquisadores do tema e para a concretização deste direito humano a todas as nossas crianças.

\section{REFERÊNCIAS}

ADRIÃO, T.; BORGHI, R. . Parcerias entre prefeituras e esfera privada: estratégias privatizantes para a oferta da educação pública em São Paulo? In: ADRIÃO, T.; PERONI, V.. Público e privado na educação; novos elementos para o debate. São Paulo: Xamã, 2008. p. 99-110

ADRIÃO, T.; BEZERRA, E. P.. O setor não lucrativo na gestão da educação pública: corresponsabilidade ou debilidade. Currículo sem Fronteiras, v. 13, n. 2, p. 256-268, mai.-ago., 2013.

ADRIÃO; T.; DAMASO, A.; GALZERANO, L. A adoção de Sistemas Privados de Ensino em escolas públicas de educação infantil: reflexão a partir do perfil dos professores. Revista e-Currículum. São Paulo: v. 2, n. 11, p. 434-460, ago. 2013. Disponível em: https://revistas.pucsp.br/curriculum/article/view/16616 - Acesso em: 26 de ago. 2020

ADRIÃO, T. A privatização dos processos pedagógicos: Grupos editoriais e os negócios na educação básica. In: MARINGONI, G. (org). O negócio da Educação. São Paulo: Olho D’água e Fapesp. 2017. p. 129- 144.

ADRIÃO, T.; DOMICIANO, C. A Educação Pública e as Corporações. Revista de Financiamento da Educação, Porto Alegre, v. 8, n. 3, p. 1-18, 2018.

ADRIÃO, T. Dimensões e formas da privatização da educação no Brasil: caracterização a partir de mapeamento de produções nacionais e internacionais. Currículo sem Fronteiras, v. 18, n. 1, p. 8-28, jan.-abr., 2018.

ARELARO, L. A não-transparência nas relações público- privadas: o caso das creches conveniadas. In: ADRIÃO, T.; PERONI, V. (org.). Público e Privado na Educação: novos elementos para o debate, São Paulo: Xamã, 2008, v. 1, p. 51-66

BASSI, M.E. Financiamento da educação infantil em seis capitais brasileiras. Cadernos de Pesquisa, v. 41, p. 116-141, 2011.

BRASIL. Lei no 8.069, de 13 de junho de 1990. Dispõe sobre o Estatuto da Criança e do Adolescente e dá outras providências. Diário Oficial da União, Brasília, 1990. Disponível em: http://www.planalto.gov.br/ccivil_03/leis/18069.htm. Acesso em: 25 jun. 2020.

BRASIL. Emenda Constitucional n ${ }^{\circ}$ 14, 12/09/1996. Diário Oficial da União, Brasília, Seção I, p. 18.109, 13/09/1996.

BRASIL. Lei no 9.394, de 20 de dezembro de 1996. Estabelece as Diretrizes e Bases da Educação Nacional. Diário Oficial da União, Brasília, 1996. Disponível em: http://www.planalto.gov.br/ccivil_03/leis/19394.htm. Acesso em: 25 jun. 2020.

BRASIL. Emenda Constitucional n 19, de 19de abril de 1998. Modifica o regime e dispõe sobre princípio e normas da Administração Pública, servidores e agentes políticos, controle de despesas e finanças públicas e custeio de atividades a cargo do Distrito Federal, e dá outras providências. Diário Oficial da União, Brasília, 1998. Disponível em: 
http://www.planalto.gov.br/ccivil_03/constituicao/Emendas/Emc/emc19.htm. Acesso em: 13 maio 2007.

BRASIL. Lei Complementar $\mathbf{n}^{\mathbf{0}}$ 101, de 04 de maio de 2000. Estabelece normas de finanças públicas voltadas para a responsabilidade na gestão fiscal e dá outras providências. Disponível em: http://www.planalto.gov.br/ccivil_03/leis/lcp/lcp101.htm - Acesso em 27 de ago. 2020.

BRASIL. Emenda Constitucional n ${ }^{\mathbf{0}}$. 53, de 19 de dezembro de 2006. Dá nova redação aos arts. $7^{\circ}$, 23, 30, 206, 208, 211 e 212 da Constituição Federal e ao art. 60 do Ato das Disposições Constitucionais Transitórias. Disponível em: https://www.planalto.gov.br/ccivil_03/Constituicao/Emendas/Emc/emc53.htm. Acesso em 10 de dez. 2008.

CAMPOS, M. M. Pré-escola: entre a educação e o assistencialismo. Cadernos de Pesquisa. São Paulo, n. 53, mai., p. 21-24, 1985. Disponível em: file://C:/Users/cassi/Downloads/1374-5211-1-PB.pdf acesso em 04 set. 2020.

CAMPOS, M. M.; ROSEMBERG, F.; FERREIRA, I. M.. Creche e Pré-escola no Brasil. 4. ed. São Paulo: Cortez; Fundação Carlos Chagas, 2006.

CORREA, B. Políticas de Educação Infantil no Brasil: ensaio sobre os desafios para a concretização de um direito. Jornal de Políticas Educacionais. Curitiba: n. 9, 2011, p. 20-29. Disponível em: http://www.jpe.ufpr.br/n9_3.pdf. Acesso em 26 de ago. 2020.

DOMICIANO, C. A. O Programa 'Bolsa Creche' nos municípios paulistas de Piracicaba e Hortolândia: Uma proposta para alocação de recursos estatais à educação privada? 228 f. Dissertação (Mestrado em educação) - Instituto de Biociências de Rio Claro, Universidade Estadual Paulista, Rio Claro, 2009.

DOMICIANO, C. A. O Projeto 'Nave-mãe' no município paulista de Campinas e os Objetivos para o Desenvolvimento do Milênio: tendências de privatização da educação infantil. Revista Políticas Educativas. Porto Alegre, v. 6, n. 1, 2012, p. 90-106.

DOMICIANO, C. A. A educação infantil via programa bolsa creche: o caso do município paulista de Hortolândia. Educ. rev., Belo Horizonte, v. 27, n. 3, p. 231-250, Dec. 2011. Disponível em: $<$ http:/ / www.scielo.br/scielo.php?script=sci_arttext\&pid=S010246982011000300012\&lng=en\&nrm=iso >. Acesso em: 11 set. 2020.

DOMICIANO-PELLISSON, C. A.;. A cogestão dos Centros de Educação Infantil 'Nave-mãe’: uma parceria público-privada analisada. Tese de Doutorado. Faculdade de Educação. Universidade Estadual de Campinas, Campinas, 2016.

FREITAS, L. C. de. Os empresários e a política educacional: como o proclamado direito à educação de qualidade é negado na prática pelos reformadores empresariais. In: Germinal: Marxismo e educação em debate. Salvador: v. 6, n. 1, p. 48-59, jun. 2014. Disponível em:

https://portalseer.ufba.br/index.php/revistagerminal/article/view/12594/8857. Acesso em 26 de ago. 2020.

FRANCO, D. S.; DOMICIANO, C. A.; ADRIÃO, T. Privatização das creches em São Paulo e seus efeitos sobre a qualidade da oferta. Teoria e Prática da Educação, v. 22, p. 80-96, 2019. 
GARCIA, T.; ADRIÃO, T.; BORGHI, R. A Nova Gestão Pública e o contexto brasileiro. In:

MARTINS, Â. M. (Org.). Instituições educacionais: políticas, gestão e práticas profissionais. Santos: Editora Universitária Leopoldianum, 2009. p. 13-26.

HILL, D.. O neoliberalismo global, a resistência e a deformação da educação. Currículo sem Fronteiras, v. 3, n. 2, p. 24-59, jul.-dez., 2003.

JUNQUILHO, G. S. Reforma gerencial o "gerente caboclo" frente os desafios da reforma do Estado no Brasil. In: CONGRESO INTERNACIONAL DEL CLAD SOBRE LA REFORMA DEL

ESTADO Y DE LA ADMINISTRACIÓN PÚBLICA, 7., 2002, Lisboa. Anais [...]. Lisboa, Portugal, 2002, p. 1-23.

JUNQUILHO, G. S. Nem "burocrata" nem "novo gerente": o "caboclo" e os desafios do Plano Diretor de Reforma do Estado no Brasil do real. Revista de Administração Pública. Rio de Janeiro, v. 38, n. 1, jan.-fev., p. 137-156, 2004.

OLIVEIRA, C. A municipalização do ensino brasileiro. In: OLIVEIRA, C. de et al. Municipalização do Ensino no Brasil. Belo Horizonte: Autêntica, 1999. p. 11-36.

OLIVEIRA, J. S.; BORGHI, R. F. Arranjos institucionais entre o poder público municipal e instituições privadas para oferta de vagas na educação infantil. Revista Brasileira de Estudos Pedagógicos, Brasília, v. 94, n. 236, p. 150-167, jan.-abr., 2013. Disponível em: https://www.scielo.br/pdf/rbeped/v94n236/08.pdf. Acesso em: 27 maio 2020.

OLIVEIRA, D. A. Nova Gestão Pública e governos democrático-populares: contradições entre a busca da eficiência e a ampliação do direito à educação. In: Educação e Sociedade. Campinas: v.36, n. 132, p. 625-646, jul.-set. 2015.

PERONI, V.. Política educacional e o papel do estado. São Paulo: Xamã, 2003.

PERONI, V.; ADRIÃO, T.. Público não-estatal: estratégias para o setor educacional brasileiro. In: ADRIÃO, Theresa; PERONI, Vera. (Orgs.). O Público e o privado na educação: interfaces entre o Estado e Sociedade. São Paulo: Xamã, 2005. p. 138-153.

PERONI. V. M. V.; OLIVEIRA, R. T. C. de.; FERNANDES, M. D. E.. Estado e terceiro setor: as novas regulações entre o público e o privado na gestão da educação básica brasileira. In: Educação e Sociedade. Campinas: v.30, n. 108, p. 761-778, out. 2009.

PINTO, J. M. R. A política recente de fundos para o financiamento da educação e seus efeitos no pacto federativo. Revista Educação e Sociedade. Campinas, v. 28, n. 100, p. 877-897, 2007. Disponível em: https://www.scielo.br/scielo.php?script=sci_arttext\&pid=S0101-73302007000300012. Acesso em: 25 jun. 2020.

PIRES, D. O. O histórico da relação público-privado e a formação do Estado Nacional: implicações para a constituição da esfera pública. In: PERONI, V. M.V. (Org.). Diálogos sobre as redefinições no papel do Estado e nas fronteiras entre o público e o privado na educação. São Leopoldo: Oikos, 2015, v. 1, p. 1-326.

REZENDE, F. Federalismo fiscal: em busca de um novo modelo. In: OLIVEIRA, R.; SANTANA, W. (Orgs). Educação e Federalismo no Brasil: combater as desigualdades, garantir a diversidade. Brasília: Unesco, 2010. p. 71-88. Disponível em: http://bibliotecadigital.puccampinas.edu.br/services/e-books/187336por.pdf\#page=69. Acesso em: 26 de ago. 2020 
SUSIN, M.O.K. O público "não-estatal": um estudo das Creches Comunitárias em Porto Alegre. In: PERONI, V.M.V; BAZZO, V. L.; PEGORARO, L. (Orgs.). Dilemas da Educação Brasileira em Tempos de Globalização Neoliberal: entre o público e o privado. Porto Alegre: UFRGS, 2006, v. 1, p. 119-140. 